\title{
Intraoperative oxygen embolus and tension pneumocephalus: Is hydrogen peroxide the culprit?
}

\author{
Supriya Dsouza, Anil Parakh1', Chitra Sarma', Adarsh Kulkarni², Ajit Baviskar
}

\begin{abstract}
Hydrogen peroxide $\left(\mathrm{H}_{2} \mathrm{O}_{2}\right)$ irrigation is commonly utilised in neurosurgical and non-neurosurgical procedures for its bactericidal and haemostatic effects. Tension pneumocephalus and venous air embolism are potentially disastrous neurological complications mostly seen after intracranial surgery in sitting position and trauma. We present a case of oxygen embolus and tension pneumocephalus after $\mathrm{H}_{2} \mathrm{O}_{2}$ irrigation during craniotomy in supine position.
\end{abstract}

Key words: Embolism, hydrogen peroxide, tension pneumocephalus

\section{INTRODUCTION}

Hydrogen peroxide $\left(\mathrm{H}_{2} \mathrm{O}_{2}\right)$ has been historically used mainly as a haemostatic agent after intracranial parenchyma resection. ${ }^{[1]}$ Its exact mechanism of haemostasis is unknown but has been postulated to arise from a combination of its vasoconstrictive and vaso-occlusive effects on blood vessels. ${ }^{[2]}$ Its action is due to the large quantity of reactive oxygen species liberated during its contact with tissues and the exothermic chemical reaction. However, it has been associated with devastating complications such as tension pneumocephalus, oxygen embolism and even dysrhythmias. ${ }^{[3]}$

\section{CASE REPORT}

We present a case of a 54-year-old male, controlled diabetic, who presented to our hospital with a history of

Departments of Critical Care and ${ }^{1}$ Anaesthesiology, Global Hospitals, ${ }^{2}$ Department of Anaesthesiology, Seth GS Medical College and KEM Hospital, Mumbai, Maharashtra, India

Address for correspondence:

Dr. Supriya Dsouza, Department of Critical Care, Global Hospitals, Mumbai, Maharashtra, India.

E-mail: supriyalynettedsouza@yahoo.com

\begin{tabular}{|l|l|}
\hline \multicolumn{2}{|c|}{ Access this article online } \\
\hline Quick Response Code: & Website: \\
\hline & www.jnaccjournal.org \\
\cline { 2 - 3 } & \\
\hline & \\
\hline
\end{tabular}

head trauma 2 months ago. He then developed symptoms of intermittent high-grade fever, vomiting, headache on and off. Computed tomography (CT) scan revealed right subgaleal and subdural empyema secondary to parietal bone osteomyelitis. He was subsequently posted for a craniotomy for drainage of the empyema in the supine position.

On pre-anaesthetic examination, the patient was conscious oriented, haemodynamically stable. There was no history of loss of consciousness, convulsions, chest trauma and ENT bleed following the trauma. Cardiac and respiratory examinations were normal. Neurological examination revealed no focal neurological deficits with a Glasgow Coma Score of 15/15. Routine investigations revealed no anomalies.

In the operation theatre, the patient was sedated with midazolam $2 \mathrm{mg}$ intravenous (IV), fentanyl 150 micrograms IV, subsequently induced with propofol $150 \mathrm{mg}$ IV and vecuronium $6 \mathrm{mg}$ IV. Airway was secured with an $8 \mathrm{~mm}$ endotracheal tube. Oxygen, air and desflurane were used for maintenance of anaesthesia. Craniotomy was performed in supine poistion and wash was given with dilute $3 \% \mathrm{H}_{2} \mathrm{O}_{2}$. Following this, within $2 \mathrm{~min}$, the end-tidal $\mathrm{CO}_{2}$ dropped from 37 to $19 \mathrm{mmHg}$

This is an open access article distributed under the terms of the Creative Commons Attribution-NonCommercial-ShareAlike 3.0 License, which allows others to remix, tweak, and build upon the work non-commercially, as long as the author is credited and the new creations are licensed under the identical terms.

For reprints contact: reprints@medknow.com

How to cite this article: Dsouza S, Parakh A, Sarma C, Kulkarni A, Baviskar A. Intraoperative oxygen embolus and tension pneumocephalus: Is hydrogen peroxide the culprit?. J Neuroanaesthesiol Crit Care 2017;4:114-6. 
and the blood pressure fell from $110 / 60$ to $80 / 50 \mathrm{mmHg}$. There was no significant blood loss till that time to attribute to the hypotension. As there was no central line in place, embolism was managed with Durant position, fluids and phenylephrine boluses. About 100\% oxygen was administered; there was no desaturation on the pulse oximeter. Haemodynamic parameters came back to baseline; surgery was continued without any major intraoperative complication. Blood loss was around $100 \mathrm{ml}$, no blood or blood products were needed. At the end of the procedure, severe hypertension (from 130/84 to $222 / 120 \mathrm{mmHg}$ ) and bradycardia (from $104 / \mathrm{min}$ to $60 /$ $\mathrm{min}$ ) were noted, pupils were sluggish and dilated. The patient was rushed on a portable ventilator to CT room urgently which showed massive right temporoparietal and occipital pneumocephalus with underlying mass effect and significant midline shift of $7.6 \mathrm{~mm}$ and generalised cerebral oedema [Figure 1]. The patient was rushed back to the operation theatre. Fentanyl 200 micrograms IV with vecuronium $5 \mathrm{mg}$ IV were given, and emergency burr hole for release of the pneumocephalus was done. The sutures were reopened, Site thoroughly irrigated with normal saline. The haemodynamic parameters gradually stabilised and remained stable throughout the surgery. At the end of the surgery, pupils were equal and reactive. The patient was shifted to the Intensive Care Unit, sedated with fentanyl infusion and mechanically ventilated. Lack of neurological recovery on the next day prompted a magnetic resonance imaging brain which showed right middle and anterior cerebral artery infarcts and left cerebellar infarcts, with residual right frontotemporoparietal pneumocephalus with an increase in midline shift and mass effect. There was no neurological recovery $48 \mathrm{~h}$ after the second surgery, and he died on the $2^{\text {nd }}$ post-operative day.

\section{DISCUSSION}

$\mathrm{H}_{2} \mathrm{O}_{2}$ is a liquid stabiliser which is commonly used as an irrigating agent for superficial wounds. Used as a typical disinfectant, solution of $\mathrm{H}_{2} \mathrm{O}_{2}$ is in low concentration, either $3 \%$ or $6 \%$. It is used intraoperatively for its haemostatic and bacteriostatic qualities. The use of $\mathrm{H}_{2} \mathrm{O}_{2}$ intraoperatively is however not without problems. Complications associated with its use are oxygen embolism, tension pneumocephalus, dysrhythmias and even cardiac arrest. The rate of cardiovascular complications is up to $3 \%{ }^{[3]}$

Although its mechanism of action for haemostasis is unknown, several hypotheses have been proposed, among which are vasoconstriction, platelet aggregation, thrombus formation and small blood vessel occlusion due to microbubbles. ${ }^{[4]} \mathrm{H}_{2} \mathrm{O}_{2}$ is decomposed by many substances, including catalases and peroxidases in blood which promote its catalysis according to the reaction: $2 \mathrm{H}_{2} \mathrm{O}_{2} \rightarrow 2 \mathrm{H}_{2} \mathrm{O}+\mathrm{O}_{2}$, and $\mathrm{O}_{2}$ release effervescent bubbles having a bactericidal and bacteriostatic effect, mainly for anaerobic microbes. Knowing their oxygen release is important because $1 \mathrm{ml}$ of $\mathrm{H}_{2} \mathrm{O}_{2}$ is capable of releasing $10 \mathrm{ml}$ of oxygen. ${ }^{[5]}$ Studies have shown that excess $\mathrm{H}_{2} \mathrm{O}_{2}$ combines with nitric oxide producing superoxide which then forms peroxynitrite through combination reactions with nitric oxide. This peroxynitrite is a potent oxidant and

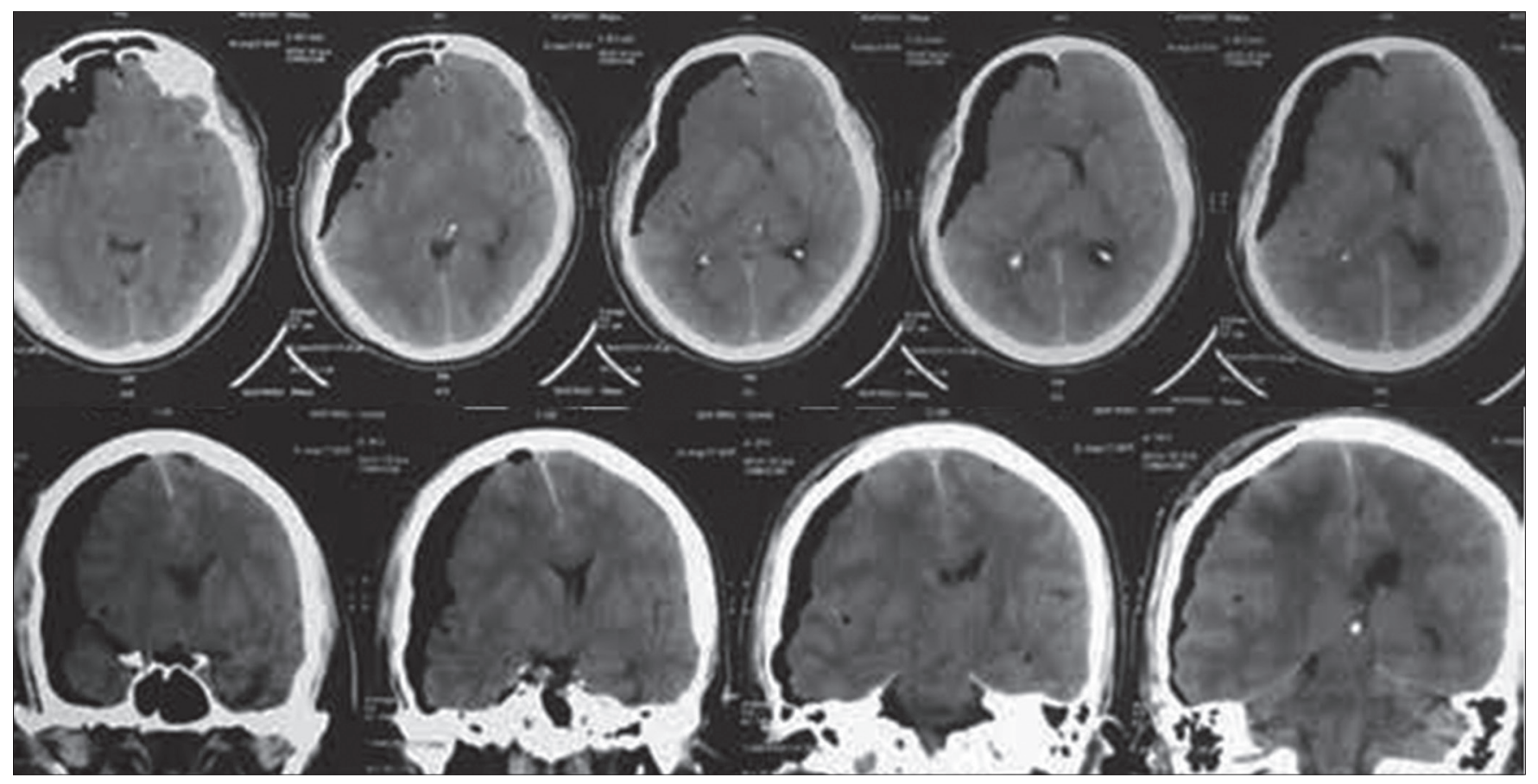

Figure 1: Computerised tomography scan sagittal and coronal views showing massive right temporoparietal and occipital pneumocephalus with underlying mass effect, significant midline shift of $7.6 \mathrm{~mm}$ and generalised cerebral oedema 
studies have shown an association between this molecule and mitochondrial respiratory dysfunction after traumatic brain injury. ${ }^{[6]}$ The Mesiwala et al. study has reported brain parenchymal-stromal vaculisation and degeneration of neurons, astrocytes and microglia up to $1 \mathrm{~mm}$ beyond the tumour resection cavity in human brains, after treatment for 5 min with $3 \% \mathrm{H}_{2} \mathrm{O}_{2}$ soaked cotton balls. ${ }^{[7]}$

Gaseous emboli result from a direct passage of gaseous oxygen into the systemic circulation by high intracavitary pressure or intravascular absorption of $\mathrm{H}_{2} \mathrm{O}_{2}$ with the secondary formation of bubbles. These complications are seen especially in cases with the use of large volumes, injection with high pressures, injection into closed and semi-closed cavities and hypovolemic patients. ${ }^{[8]}$

The trigemino-cardiac reflex (TCR) is a well-known clinical phenomenon described during craniofacial or skull base surgery as well as neuroradiological interventions and defined as the sudden onset of parasympathetic dysrhythmia, sympathetic hypotension, apnoea or gastric hypermotility during intraoperative stimulation of any of the sensory branches of the trigeminal nerve. ${ }^{[9]}$ Spiriev et al. have described a case of TCR occurrence during drainage of subdural haematoma where $\mathrm{H}_{2} \mathrm{O}_{2}$ was used. They attribute the occurrence to liberated oxygen from $\mathrm{H}_{2} \mathrm{O}_{2}$ exerting a substantial concomitant chemical stimulation on a large dural surface innervated by $\mathrm{V} 2$ and V3. Stimulation of these trigeminal dural afferents might be the cause of central TCR initiation. ${ }^{[10]}$

Huang and Pik have described a case of tension pneumocephalus due to oxygen liberation after $\mathrm{H}_{2} \mathrm{O}_{2}$ use in a case of temporal lobe tumour. ${ }^{[11]}$

Beattie et al. have described a case of cardiac arrest after $\mathrm{H}_{2} \mathrm{O}_{2}$ irrigation of a breast wound. ${ }^{[12]}$

The utilisation of $\mathrm{H}_{2} \mathrm{O}_{2}$ during intracranial interventions, especially near vital brain centres (hypothalamus and brainstem) and trigeminally innervated intracranial structures (dura mater and large cerebral vessels) should be regarded with caution because of the possible risks for cardiovascular complications. Prompt communication with the surgeon and a greater vigilance is necessary during $\mathrm{H}_{2} \mathrm{O}_{2}$ irrigation. Cardiac dysrhythmias should be kept in mind and added to the already known possible complications (venous embolism and post-operative pneumoce phalus) related to the intraoperative use of $\mathrm{H}_{2} \mathrm{O}_{2} \cdot{ }^{[10]}$
Despite the complications associated with its use, $\mathrm{H}_{2} \mathrm{O}_{2}$ is still used frequently, especially in developing countries, with little knowledge of its inherent complications.

$\mathrm{H}_{2} \mathrm{O}_{2}$ is not more effective than other antiseptics, also the potential complications associated with its use should be recognised. The alternative use of saline seems very reasonable.

\section{Financial support and sponsorship}

Nil.

\section{Conflicts of interest}

There are no conflicts of interest.

\section{REFERENCES}

1. Epstein JA. Hydrogen peroxide for hemostasis. Neurosurgery 1987;20:63.

2. Szabó C, Ischiropoulos H, Radi R. Peroxynitrite: Biochemistry, pathophysiology and development of therapeutics. Nat Rev Drug Discov 2007;6:662-80.

3. Gyanesh P, Haldar R. Hemodynamic derangements with hydrogen peroxide instillation in neurosurgery: Need for awareness among anesthesiologists and surgeons. World Neurosurg 2014;82:e388-9.

4. Mullins ME, Beltran JT. Acute cerebral gas embolism from hydrogen peroxide ingestion successfully treated with hyperbaric oxygen. J Toxicol Clin Toxicol 1998;36:253-6.

5. Loeb T, Loubert G, Templier F, Pasteyer J. Iatrogenic gas embolism following surgical lavage of a wound with hydrogen peroxide. Ann Fr Anesth Reanim 2000;19:108-10.

6. Singh IN, Sullivan PG, Hall ED. Peroxynitrite-mediated oxidative damage to brain mitochondria: Protective effects of peroxynitrite scavengers. J Neurosci Res 2007;85:2216-23.

7. Mesiwala AH, Farrell L, Santiago P, Ghatan S, Silbergeld DL. The effects of hydrogen peroxide on brain and brain tumors. Surg Neurol 2003;59:398-407.

8. Donati S, Barthélémy A, Boussuges A, Gainnier M, Ayem ML, Romanet $\mathrm{S}$, et al. Severe air embolism after surgical irrigation with hydrogen peroxide. Presse Med 1999;28:173-5.

9. Schaller B, Probst R, Strebel S, Gratzl O. Trigeminocardiac reflex during surgery in the cerebellopontine angle. J Neurosurg 1999;90:215-20.

10. Spiriev T, Tzekov C, Kondoff S, Laleva L, Sandu N, Arasho B, et al. Trigemino-cardiac reflex during chronic subdural haematoma removal: Report of chemical initiation of dural sensitization. JRSM Short Rep 2011;2:27.

11. Huang C, Pik J. Tension pneumocephalus and oxygen emboli from hydrogen peroxide irrigation. J Clin Neurosci 2014;21:323-5.

12. Beattie C, Harry LE, Hamilton SA, Burke D. Cardiac arrest following hydrogen peroxide irrigation of a breast wound. J Plast Reconstr Aesthet Surg 2010;63:e253-4. 